\title{
The Positive Impact of Red Songs on College Students' Anxiety
}

\author{
Shuyi $\mathrm{Ma}^{1, \mathrm{a}}$ \\ ${ }^{1}$ School of Music,University of Jinan,Jinan,250000, China \\ ${ }^{a}$ Email:M2412407382@163.com
}

\begin{abstract}
In this paper, in order to investigate whether red songs have a positive and effective effect on anxiety in college student groups, the Positive Psychological Quality Scale and the Self-Assessment of Anxiety Scale (SAS) for Chinese College Students were used as experimental measurement tools, and this experimental design was conducted on 123 college student subjects, and 82 were randomly selected and divided into a control group and an experimental group, with 41 students in each group. The experimental results showed that (1) gender, age and whether the college students were only children were not correlated with the measured positive psychological qualities of Chinese college students and college students' anxiety self-ratings. (2) The anxiety self-ratings of college students with no music background were significantly higher than the anxiety self-ratings of college students after listening to red songs. (3) The positive psychological quality scores of college students without music were significantly lower than those of college students after listening to red songs.
\end{abstract}

Keywords: red songs, anxiety, positive music

\section{INTRODUCTION}

As society continues to develop and the pace of life continues to accelerate, the number of anxious college students continues to grow. Anxiety is gradually becoming a common negative emotion, which has obvious adverse effects on the physical and mental health and academic performance of college students. It is well known that listening to music can regulate negative emotions and relieve psychological stress. A unique form of intervention, music therapy, has come into the public eye, and music therapy can be achieved through music appreciation, simple instrument playing, singing songs, and interactive music games [1]. Some studies have indicated that there is also a lot of music available in the West that can be used as music therapy pieces that can relatively treat insomnia and anxiety that are common among college students [2].

The musical characteristics of positive music have an important influence on psychological regulation. Modern medical and psychological research has shown that the frequency and sound pressure of musical sound waves cause physiological and psychological reactions that can effectively relieve tension, anxiety, depression and other negative psychology caused by subjective and objective factors [3]. And positive music includes red songs, so how do the positive emotions of red songs affect the psychological emotions? Red songs can be explored in terms of background, lyrics, and tunes. The source and formation of red songs itself has constituted the advantageous conditions that are easy for people to accept, the intention is natural, popular and positive [4] and the lyrics are mostly from folk life, simple and unpretentious, easy to trigger the feelings of empathy. Of course, red songs also contain many different types of tunes and emotions. Masculine works include those reflecting man's struggle with nature and with fate, which can make students' wills strong; music with grand structure and surging momentum can make students broad-minded and resolute [5]. However, no studies have been conducted to illustrate the ability of red songs to intervene to alleviate the emotions of college students, as well as targeted and effective measures. In addition to the above effects of regulating psychological emotions, red songs have a positive impact on improving self-awareness and achieving self-worth. Red songs can, improve attention, judgment and memory [2], which in turn can improve one's cognition.

Therefore, this study argues that red songs will increase college students' self-awareness while having a positive impact on anxiety psychology. Using the 
college student population as the target, this issue is verified and analyzed through experimental methods, and the results provide effective intervention methods, thus providing an in-depth exploration of school education with certain reference suggestions for college students' efforts to alleviate anxiety psychological disorders.

\section{METHOD}

\subsection{Subjects of the Study}

In this study, 123 general college subjects, aged $18-25$, all of whom were college students living in mainland China for a long time, 35 male and 88 female, were assessed on the Positive Psychological Quality Scale and the Self-Assessment Scale (SAS) for Chinese college students. A total of 41 students, 34 girls and 7 boys, were selected as the control group; a total of 41 students, 33 girls and 8 boys, were selected as the experimental group for listening to red songs.

\subsection{Experimental Design}

The experimental design was conducted using no music and listening to red songs as two factors, with red songs as the independent variable, the dependent variable being anxiety, and the control variables being song repertoire, gender, grade level, and whether the child was an only child.

\subsection{Research Tools}

\subsubsection{Positive Mental Quality Scale for Chinese College Students}

In this study, the Positive Mental Quality Scale for Chinese College Students, jointly developed by Meng Wanjin and Guan Qun, was used, which is a self-assessment scale with 62 items divided into six dimensions: cognitive, affective, interpersonal, fairness, moderation and transcendence [6]. The scale has good reliability and validity, easy and quick to operate, and can reflect the level of positive psychological qualities of the subjects in a more comprehensive and scientific way, which can be used as a preliminary measurement tool for large scale assessment and related studies [7].

\subsubsection{Anxiety Self-Assessment Scale (SAS)}

The Self-Assessment Scale for Anxiety (SAS) used is a measurement tool developed by Zung in 1971, which is also a self-rating scale containing 20 items on a 4-point scale to assess the subjective feelings of anxious patients [8]. The scale has been widely used and is more accepted for use both nationally and internationally.

\subsubsection{Red Songs}

The songs are chosen from the popular, "Shining Red Star" movie episode "Ying Shan Hong" sung by famous singer Han Hong, and two songs "The Country" sung by renowned actor Jackie Chan and singer Liu Yuanyuan.

\subsection{Experimental Procedures}

The measurement parts of this experiment were done on the tested electronic devices, and the specific experimental procedures were as follows: $\square$ To achieve the state of psychological anxiety, all subjects filled in the Positive Psychological Quality Scale for Chinese University Students and the Self-Assessment of Anxiety Scale (SAS) after the holidays and before the start of the new semester. $\square$ After an hour break, subjects in the experimental group listened to the song "Country" and, after listening to it, refilled the Self-Assessment Scale of Anxiety (SAS); then listened to the song "Ying Shan Hong" and refilled the Positive Psychological Quality Scale for Chinese College Students. In the control group, without any intervention, the subjects refilled the Positive Psychological Quality Scale for Chinese College Students and the Self-Assessment Scale for Anxiety (SAS), and after completion, they were uniformly retrieved. $\square$ After the experiment, the purpose of the experiment was explained to the subjects.

\section{RESULTS}

Preliminary correlations were analyzed statistically by analyzing control variables and between subjects' positive psychological qualities and anxiety self-ratings, and the results are shown in Table 1.

Table 1. Statistical table of correlations between control variables and subjects' positive psychological qualities and anxiety self-ratings $(n=123)$

\begin{tabular}{cccc}
\hline & gender & grade & $\begin{array}{c}\text { Being an } \\
\text { only child or } \\
\text { not }\end{array}$ \\
\hline $\begin{array}{c}\text { Positive } \\
\text { psychological } \\
\text { qualities } \\
\text { anxiety }\end{array}$ & 0.050 & -0.038 & 0.131 \\
self-assessment & 0.063 & -0.076 & -0.142 \\
\hline
\end{tabular}

* $p<0.05$ ** $p<0.01$

Table 1 shows that none of the control variables gender, grade, whether or not an only child and positive psychological quality, anxiety self-assessment show significance, all correlation coefficient values are close to 0 and all $\mathrm{p}$-values are greater than 0.05 , indicating that there is no correlation between the control variables 
gender, grade, whether or not an only child and positive psychological quality, anxiety self-assessment.

Then, paired t-test analysis of the two groups, control and experimental, on anxiety self-ratings then revealed that the data showed a difference between the two groups, with a 0.01 level of significance $(t=4.691$, $\mathrm{p}=0.000$ ) between the anxiety self-ratings (control group) and the anxiety self-ratings (experimental group). The mean of the anxiety self-ratings (control group) was (1.57) and the mean of the anxiety self-ratings (experimental group) was (1.45), and the difference between their specific comparison can be seen that the control group was significantly higher than the experimental group in terms of the mean of the anxiety self-ratings. Thus, anxiety without music is significantly stronger than anxiety after listening to red songs, and anxiety changes depending on the emotion after listening to red songs.

Similarly, a paired t-test analysis of the two groups, control and experimental, on the positive psychological quality measure revealed that a 0.01 level of significance $(\mathrm{t}=-11.841, \mathrm{p}=0.000)$ was presented between the positive psychological quality (control group) and the positive psychological quality (experimental group). Comparing the differences it was obtained that the mean of the positive psychological (control group) (1.90), would be significantly lower than the mean of the positive psychological (experimental group) (2.13). Therefore, the positive psychological quality scores were higher after listening to the red songs than the no music positive psychological quality scores, and the positive psychological quality would likewise differ depending on how one felt after listening to the red songs.

\section{DISCUSSION}

In this study, the effect of red songs on anxiety was studied through two scales, and it was found that listening to red songs has a moderating effect on college students' anxiety, while listening to red songs can have a positive and effective effect. Therefore, in practical application, for the anxiety of college students college ideological education can be alleviated and regulated by listening to red songs in groups. In the two subsequent paired t-tests, the results of both times show that different psychological states produce different effects after listening to red songs, and red songs can intervene in college students' emotions, which is in line with the hypothesis of the original expectations and questions. However, this study only focuses on the effective impact of individuals after listening to red songs, while there is a big difference in the impact produced by groups singing red songs, and whether it will have an effective impact on the positive emotions of the group, which is the issue that will be focused on in the follow-up study.
In summary, listening to red songs will have a positive impact on college students' anxiety psychology, and those with stronger anxiety are more likely to feel the obvious impact, which has certain inspiration for the ideological education system in colleges. The strong promotion of red culture in colleges can enable university students to take a more positive attitude towards problems in the midst of stress, reduce doubt and denial of self, improve self-awareness and soothe and release stress.Red songs can be integrated into the cultivation and education of college students, such as playing red songs during classes, carrying out more research and discussion activities for red songs, red song speech and creation competition, etc. to make red ideological education penetrate into the hearts of contemporary college students.

\section{CONCLUSION}

The following conclusions can be drawn from this study: $\square$ There was no significant correlation between anxiety, positive psychological qualities of college students and gender, age, and whether they were only children. $\square$ Anxiety after listening to red songs is lower than anxiety without music. $\square$ Positive psychological quality after listening to red songs is significantly higher than positive psychological quality under no music.

\section{REFERENCES}

[1] Zhang, H. X. (2011). Singing therapy's intervention for isolation in interpersonal communication among college students. Art 100,367-369.

[2] Liu, G.Z., Deji, Y.Z. (2019). A study on the intervention of music therapy on negative emotions of college students. Contemporary Education and Culture (01),86-90.

[3] Yu, X.Y. (2013). The impact of music therapy on college students' mental health. Journal of Hubei Second Normal College,99-100.

[4] Jiang, F.,Li, X.L. (2012). The psychological orientation function of ideological and political education of red songs--Taking Dabie Mountain red songs as an example. Journal of Three Gorges University (Humanities and Social Sciences Edition), 28-30+52.

[5] Zhan, V. (2004). Music appreciation and the cultivation of contemporary college students' mental health. Journal of Southwest University for Nationalities (Humanities and Social Sciences Edition) (09), 401-402.

[6] Song, W.W.,Wu, L.L. (2013). A study on the current situation of positive psychological quality development and educational countermeasures among art college students in colleges and 
universities. China Special Education(04),72-77.

[7] Meng, W.J., Gua,Q. (2009). Report on the development of the Positive Mental Quality Scale for Chinese college students. China Special Education, 73-79.

[8] Wang, Zh.Y., Chi, Y.F. (1984). Anxiety Self-Assessment Scale (SAS). Shanghai Psychiatry (02), 73-74. 